\title{
Optimasi Suhu dan Waktu pada Proses Pengeringan Manisan Cabai Merah (Capsicum annuum L.) Menggunakan Tunnel Dehydrator
}

\section{Optimization of Temperature and Time in the Process of Drying Red Chili (Capsicum annuum L.) Candy using Tunnel Dehydrator}

\author{
Hisworo Ramdani ${ }^{12^{*}}$, Badru Tamam ${ }^{3}$ \\ ${ }^{1}$ Program Studi Ilmu dan Teknologi Pangan, Fakultas Bioindustri, Universitas Trilogi, Jakarta \\ ${ }^{2}$ Pusat Kajian Hortikultura Tropika, Lembaga Penelitian dan Pengabdian pada Masyarakat Institut Pertanian Bogor, \\ Jl. Raya Pajajaran, Kampus IPB Baranangsiang, Bogor, Indonesia \\ ${ }^{3}$ Program Studi Teknologi Industri Pertanian, Fakultas Ilmu Pangan Halal, Universitas Djuanda Bogor
}

Diterima 11 Mei 2018/Disetujui 11 Juni 2018

\begin{abstract}
The research aimed to obtain the optimal conditions of temperature and time factor in the drying process sweetened red chili based on the value of the parameters analyzed, namely the levels of colour (chroma value), vitamin C content, water content, and sugar content. The study was conducted by using Response Surface Methodology (RSM). The first factor is the drying temperature with minimal limit of $50^{\circ} \mathrm{C}$ and maximal limit of $80^{\circ} \mathrm{C}$. The second factor is the drying time with minimal limit 2 hours and maximal limit 5 hours. The combination of these two factors resulted in 13 units of the experiment with two replications. Optimal conditions sweetened dried red chili achieved resulting in the combination of drying temperature 73.36 ${ }^{\circ} \mathrm{C}$ and drying time 2.54 hours with a chroma value of 21.22 , vitamin C content of $5.8 \mathrm{mg} / 100 \mathrm{~g}$, water content of $10.56 \%$, and sugar content of $49.82^{\circ} \mathrm{Brix}$.
\end{abstract}

Keywords : red chili, sweetened, optimization, tunnel dehydrator, RSM

\section{ABSTRAK}

Penelitian bertujuan untuk mendapatkan kondisi optimal dari faktor suhu dan waktu pada proses pengeringan manisan cabai merah berdasarkan nilai dari parameter yang dianalisis yaitu nilai warna (nilai chroma), kadar vitamin C, kadar air, dan kadar gula total. Penelitian dilakukan dengan menggunakan Metode Permukaan Respon/Response Surface Methodology (RSM). Faktor pertama yaitu suhu pengeringan dengan batas minimal $50^{\circ} \mathrm{C}$ dan batas maksimal $80^{\circ} \mathrm{C}$. Faktor kedua yaitu waktu pengeringan dengan batas minimal 2 jam dan batas maksimal 5 jam. Kombinasi dari kedua faktor tersebut menghasilkan 13 unit percobaan dengan 2 ulangan. Kondisi optimal manisan kering cabai merah yang dihasilkan dicapai pada kombinasi suhu pengeringan $73.36^{\circ} \mathrm{C}$ dan waktu pengeringan 2.54 jam dengan nilai chroma 21.22 , kadar vitamin $C$ $5.8 \mathrm{mg} / 100 \mathrm{~g}$, kadar air $10.56 \%$, dan kadar gula total $49.82^{\circ}$ Brix.

Kata kunci : cabai merah, manisan, optimasi, tunnel dehydrator, RSM

\section{PENDAHULUAN}

Tanaman cabai (Capsicum annuum L.) merupakan salah satukomoditas hortikulturayang banyak dibudidayakan oleh masyarakat Indonesia. Tanaman ini bernilai ekonomi tinggi dan mempunyai daya adaptasi yang cukup luas sehingga dapat dibudidayakan pada berbagai ekosistem yang berbeda.

Persediaan cabai di pasaran melimpah terutama pada saat panen raya tiba sehingga dapat menyebabkan harga jual menjadi rendah dan resiko terjadinya pembusukan karena

\footnotetext{
* Penulis untuk korespondensi. e-mail: hisworor@gmail.com
}

melimpahnya persediaan akan semakin besar. Cabai bersifat mudah rusak, menyusut, dan cepat membusuk. Pengetahuan petani terhadap pengolahan pascapanen juga masih terbatas sehingga petani banyak yang lebih memilih menjual semua cabainya yang pada akhirnya akan menyebabkan harga cabai di pasaran menjadi turun drastis.

Kerusakan pascapanen untuk komoditas sayuran termasuk cabai di Indonesia cukup tinggi yaitu mencapai 25-40\% (Muchtadi dan Anjarsari, 1995). Hal tersebut terjadi karena adanya perubahan fisik, kimia, fisiologis atau mikroba yang terus berjalan setelah panen, sehingga berbagai alternatif penganekaragaman bentuk olahan cabai harus terus dicari agar permasalahan-permasalahan tersebut 
dapat diatasi. Usaha pengolahan buah cabai menjadi produk yang baru telah banyak dilakukan diantaranya menjadi cabai bubuk, cabai kering, saus cabai, dan manisan. Pengolahan cabai menjadi manisan basah telah banyak dilakukan masyarakat walaupun masih dalam skala kecil, sedangkan pengolahan cabai menjadi manisan cabai kering masih jarang dilakukan masyarakat mengingat prosesnya yang cukup rumit terutama pada saat pengeringan karena masyarakat sebagian besar masih menggunakan energi matahari untuk mengeringkan cabai sehingga perlu dilakukan penelitian mengenai pengolahan cabai menjadi manisan cabai kering dengan menggunakan mesin pengering. Salah satu mesin yang dapat digunakan untuk pengeringan manisan cabai adalah tunnel dehydrator.

Beberapa faktor yang dapat memengaruhi hasil pengeringan bahan pangan diantaranya suhu dan waktu pengeringan. Penggunaan suhu dan waktu pengeringan yang optimal dapat mengurangi tingkat kerusakan akibat proses pengeringan seperti kerusakan pada kadar warna dan vitamin $\mathrm{C}$ manisan cabai merah sehingga perlu dilakukan penelitian untuk mendapatkan suhu dan waktu optimal pada proses pengeringan manisan cabai merah menggunakan mesin pengering tunnel dehydrator. Penelitian ini bertujuan untuk mendapatkan kondisi optimal dari faktor suhu dan waktu pada proses pengeringan manisan cabai merah berdasarkan nilai kadar warna, kadar vitamin C, kadar air, dan kadar gula total.

\section{BAHAN DAN METODE}

Alat-alat yang digunakan adalah tunnel dehydrator, termometer, stop watch, timbangan digital (ketelitian $0.1 \mathrm{~g}$ ), colour reader CR-10 Konica Minolta, hand refractometer, plastik PP, sealer. Bahan-bahan yang digunakan adalah cabai merah besar kultivar TW, gula pasir, kalsium klorida $\left(\mathrm{CaCl}_{2}\right)$, garam, dan bahan kimia untuk analisis.
Penelitian dilakukan untuk mengetahui suhu dan waktu optimal pada proses pengeringan manisan cabai merah. Faktor pertama yaitu suhu dengan batas minimum (-1) 50 ${ }^{\circ} \mathrm{C}$ dan batas maksimum $(+1) 80^{\circ} \mathrm{C}$, sedangkan faktor kedua yaitu waktu pengeringan dengan batas minimum (-1) 2 jam dan batas maksimum (+1) 5 jam. Parameter yang diamati yaitu kadar warna, kadar vitamin C, kadar air, dan kadar gula total. Metode penelitian yang digunakan adalah Metode Permukaan Respon (Response Surface Methodology). Model rancangan percobaan yang digunakan adalah sebagai berikut :

$$
Y=a_{o}+\sum_{i=1}^{3} a_{i} X_{i}+\sum_{i<j} a_{j} X_{i} X_{j}+\sum_{i=j}^{2} a_{j} X_{i}^{2}
$$

Keterangan : $\mathrm{Y}=$ Respon dari masing-masing perlakuan, $\mathrm{a}_{0}$, $\mathrm{a}_{\mathrm{i}}, \mathrm{a}_{\mathrm{ij}}=$ Parameter regresi, $\mathrm{X}=$ Pengaruh linier faktor utama, $\mathrm{X}_{\mathrm{i}} \mathrm{X}_{\mathrm{j}}=$ Pengaruh linier dua faktor, $\mathrm{X}_{\mathrm{i}}^{2}=$ Pengaruh kuadratik faktor utama

\section{HASIL DAN PEMBAHASAN}

Faktor yang diberikan pada pembuatan manisan kering cabai merah adalah suhu dan waktu pengeringan. Respon yang akan didapatkan yaitu nilai warna (nilai chroma), kadar vitamin C, kadar air, dan kadar gula total. Semua nilai parameter yang dihasilkan diharapkan akan sesuai dengan standar mutu manisan kering buah-buahan (SII 0718-83). Hasil analisis manisan kering cabai merah dapat dilihat pada Tabel 2.

\section{Nilai Chroma}

Hasil analisis nilai chroma manisan kering cabai merah menunjukkan berbeda nyata pada taraf $\alpha=0.05$. Hal ini menunjukkan bahwa kombinasi faktor suhu dan waktu pengeringan berpengaruh terhadap nilai chroma (Tabel 2). Analisis nilai chroma menggunakan minitab menghasilkan

Tabel 1. Matriks rancangan faktorial dari masing-masing faktor

\begin{tabular}{ccccc}
\hline Run & Kode $(\mathrm{X} 1)$ & Kode $(\mathrm{X} 2)$ & Suhu pengeringan ${ }^{\circ} \mathrm{C}(\mathrm{X} 1)$ & Waktu pengeringan jam $(\mathrm{X} 2)$ \\
\hline 1 & -1 & -1 & 50 & 2 \\
2 & -1 & 1 & 50 & 5 \\
3 & 1 & -1 & 80 & 5 \\
4 & 1 & 1 & 80 & 3.5 \\
5 & 0 & 0 & 65 & 3.5 \\
6 & 0 & 0 & 65 & 3.5 \\
7 & -1.4 & 0 & 45 & 3.5 \\
8 & 1.4 & 0 & 85 & 1.4 \\
9 & 0 & -1.4 & 65 & 5.6 \\
10 & 0 & 1.4 & 65 & 3.5 \\
12 & 0 & 0 & 65 & 65 \\
\end{tabular}


fungsi $\mathrm{Y}=22.5495-0.9633 \mathrm{x}_{1}-1.1864 \mathrm{x}_{2}-0.1418 \mathrm{x}_{1}^{2}-$ $0.6042 \mathrm{x}_{2}^{2}+3.5360 \mathrm{x}_{1} \mathrm{x}_{2}$ dengan model sadel (saddle point). Bentuk saddle point menunjukkan bahwa pada data nilai chroma manisan kering cabai merah yang didapatkan tidak diperoleh kondisi optimal.

Warna manisan cabai merah yang menjadi lebih gelap setelah pengeringan dapat disebabkan oleh adanya proses pencoklatan. Semakin tinggi suhu pengeringan maka warna yang dihasilkan akan cenderung mendekati warna coklat pekat atau gelap. Hal tersebut dapat terjadi karena pada saat pengeringan terjadi proses pencoklatan atau reaksi Maillard (Wati, 2011). Deman (1997) menyatakan bahwa reaksi Maillard dapat dipicu oleh proses pengolahan seperti pengeringan. Semakin tinggi suhu pengeringan maka reaksi Maillard akan terjadi semakin cepat. Nilai chroma manisan kering cabai merah yang dihasilkan bervariasi mulai dari 17.04 sampai dengan 25.74 dengan rata-rata sebesar 22.09 (Tabel 2). Berdasarkan Sanguansri et al., (1995), nilai-nilai tersebut termasuk ke dalam kelas mutu baik sekali sampai dengan sangat baik sekali. Parameter warna menunjukkan warna yang sesuai dengan yang diinginkan.

\section{Kadar Vitamin C}

Vitamin C merupakan salah satu vitamin yang larut dalam air dan termasuk golongan vitamin antioksidan yang mampu menangkal berbagai radikal bebas. Kusnandar (2010) menyatakan bahwa vitamin C terdapat dalam semua jaringan hidup yang mempunyai tugas memengaruhi reaksi oksidasi-reduksi. Sumber utama asam L-askorbat dalam makanan adalah sayuran dan buah-buahan.

Pengamatan terhadap vitamin $\mathrm{C}$ manisan kering cabai merah hasil penelitian menunjukkan hasil yang bervariasi diantara $2.64-9.49 \mathrm{mg} 100 \mathrm{~g}^{-1}$ dengan rata-rata sebesar $6.20 \mathrm{mg} 100 \mathrm{~g}^{-1}$. Hasil analisis kadar vitamin C manisan kering cabai merah menghasilkan fungsi $\mathrm{Y}=6.58791$

Tabel 2. Hasil Analisis Manisan Kering Cabai Merah

\begin{tabular}{|c|c|c|c|c|c|c|c|}
\hline \multirow{2}{*}{ Kode } & & \multirow{2}{*}{ Suhu $\left({ }^{\circ} \mathrm{C}\right)$} & \multirow{2}{*}{ Waktu (jam) } & \multicolumn{4}{|c|}{ Analisis } \\
\hline & & & & Kadar gula total & Vitamin C & Kadar air & Warna \\
\hline \multirow{2}{*}{-1} & \multirow{2}{*}{-1} & \multirow{2}{*}{50} & \multirow{2}{*}{2} & 42 & 8.63 & 29.79 & 25.74 \\
\hline & & & & 42 & 9.49 & 30.61 & 25.06 \\
\hline \multirow{2}{*}{1} & \multirow{2}{*}{-1} & \multirow{2}{*}{80} & \multirow{2}{*}{2} & 36 & 4.31 & 8.89 & 17.18 \\
\hline & & & & 36 & 3.45 & 8.51 & 17.04 \\
\hline \multirow{2}{*}{-1} & \multirow{2}{*}{1} & \multirow{2}{*}{50} & \multirow{2}{*}{5} & 50 & 7.04 & 18.75 & 17.82 \\
\hline & & & & 50 & 7.92 & 14.00 & 18.89 \\
\hline \multirow{2}{*}{1} & \multirow{2}{*}{1} & \multirow{2}{*}{80} & \multirow{2}{*}{5} & 48 & 2.64 & 4.55 & 24.25 \\
\hline & & & & 50 & 2.64 & 2.22 & 24.17 \\
\hline \multirow{2}{*}{-1.4} & \multirow{2}{*}{0} & \multirow{2}{*}{45} & \multirow{2}{*}{3.5} & 44 & 7.84 & 30.00 & 25.69 \\
\hline & & & & 44 & 7.84 & 28.57 & 23.64 \\
\hline \multirow{2}{*}{1.4} & \multirow{2}{*}{0} & \multirow{2}{*}{85} & \multirow{2}{*}{3.5} & 46 & 3.52 & 6.25 & 20.71 \\
\hline & & & & 46 & 4.40 & 4.00 & 21.16 \\
\hline \multirow{2}{*}{0} & \multirow{2}{*}{-1.4} & \multirow{2}{*}{65} & 1 & 48 & 7.76 & 25.00 & 24.89 \\
\hline & & & 1.4 & 48 & 7.76 & 30.00 & 25.61 \\
\hline 0 & & & & 50 & 5.08 & 13.04 & 17.70 \\
\hline 0 & 1.4 & 65 & 5.6 & 50 & 5.08 & 10.64 & 19.31 \\
\hline 0 & 0 & 65 & 35 & 58 & 6.77 & 10.87 & 23.16 \\
\hline 0 & 0 & 65 & 3.5 & 58 & 6.77 & 8.51 & 23.15 \\
\hline 0 & & & 35 & 58 & 6.10 & 10.20 & 19.45 \\
\hline 0 & 0 & 65 & 3.5 & 58 & 6.04 & 10.20 & 19.83 \\
\hline a & O & 65 & 25 & 58 & 6.97 & 14.58 & 24.30 \\
\hline 0 & 0 & 65 & 3.5 & 58 & 6.97 & 14.8 & 24.30 \\
\hline 0 & 0 & & & 58 & 6.97 & 10.20 & 21.52 \\
\hline 0 & 0 & 65 & 3.5 & 58 & 6.97 & 12.00 & 23.12 \\
\hline & & & & 49 & 6.16 & 8.16 & 23.18 \\
\hline 0 & 0 & 65 & 3.5 & 49 & 6.16 & 6.25 & 23.48 \\
\hline
\end{tabular}


- $1.93823 \mathrm{x}_{1}-0.82641 \mathrm{x}_{2}-0.44233 \mathrm{x}_{1}^{2}-0.18273 \mathrm{x}_{2}^{2}+$ $0.08412 \mathrm{x}_{1} \mathrm{x}_{2}$ yang membentuk model sadel (saddle point). Vitamin $\mathrm{C}$ akan semakin menurun dengan meningkatnya pemanasan (Burdulu et al., 2006). Suhu yang semakin tinggi dapat meningkatkan kecepatan oksidasi vitamin $\mathrm{C}$ sehingga jumlah vitamin $\mathrm{C}$ yang rusak karena oksidasi per satuan waktu akan lebih banyak (Wenck et al., 1980).

\section{Kadar Air}

Pengamatan terhadap data kadar air hasil penelitian menunjukkan hasil bervariasi mulai dari $2.22 \%$ sampai dengan $30.61 \%$ dengan rata-rata sebesar $14.25 \%$. Hasil analisis ragam dengan taraf kepercayaan $\alpha=0.05$ menunjukkan bahwa pemberian faktor suhu dan waktu pengeringan memberikan pengaruh yang signifikan terhadap nilai kadar air manisan kering cabai merah.

Kadar air tertinggi didapatkan pada suhu pengeringan $50{ }^{\circ} \mathrm{C}$ dengan waktu pengeringan 2 jam yaitu sebesar $30.61 \%$, sedangkan kadar air terendah didapatkan pada suhu pengeringan $80{ }^{\circ} \mathrm{C}$ dengan waktu pengeringan 5 jam yaitu sebesar 2.22\% (Tabel 2). Taib et al., (1987) menyatakan bahwa kadar air suatu bahan berpengaruh terhadap banyaknya air yang diuapkan dan lamanya waktu pengeringan. Semakin tinggi kadar air dalam bahan maka semakin lama waktu yang dibutuhkan untuk mengeringkan bahan tersebut. Hasil analisis menunjukkan bahwa faktor suhu dan waktu pengeringan serta interaksi antara keduanya memberikan pengaruh yang nyata terhadap kadar air manisan kering cabai merah. Persamaan yang dihasilkan adalah $\mathrm{Y}=10.557-8.582 \mathrm{x}_{1}-5.161 \mathrm{x}_{2}+2.381 \mathrm{x}_{1}^{2}+3.613 \mathrm{x}_{2}^{2}$ $+2.127 \mathrm{x}_{1} \mathrm{x}_{2}$.

\section{Kadar Gula}

Pengukuran kadar gula dilakukan menggunakan alat hand refractometer. Hasil analisis terhadap kadar gula manisan kering cabai merah menunjukkan bahwa faktor suhu dan waktu pengeringan serta interaksi antara keduanya berpengaruh secara signifikan terhadap kadar gula total manisan kering cabai merah.

Gambar 1 menunjukkan surface plot kadar gula total dengan fungsi $\mathrm{Y}=56.2000-0.5214 \mathrm{x}_{1}+2.9786 \mathrm{x}_{2}-6.2875 \mathrm{x}_{1}{ }^{2}$ $-4.2875 \mathrm{x}_{2}^{2}+1.2500 \mathrm{x}_{1} \mathrm{x}_{2}$. Gambar tersebut menunjukkan bahwa dari data kadar gula total dapat ditentukan kondisi optimal. Bagian berwarna merah pada gambar tersebut menunjukkan kadar gula total tertinggi yang dihasilkan yaitu sebesar $58{ }^{\circ}$ Brix. Ketika proses pengeringan berlangsung, larutan gula akan mengalami inverse yaitu proses pemecahan sukrosa menjadi glukosa dan fruktosa. Proses pemecahan ini akan menyebabkan terjadinya peningkatan kelarutan gula dalam bahan (Achyadi, 2004). Meningkatnya kelarutan gula menyebabkan kadar sukrosa dalam bahan akan berkurang.

\section{Optimasi Faktor Reaksi}

Kondisi optimal dari kombinasi antara faktor suhu dan waktu pengeringan didapatkan pada suhu pengeringan
$73.36{ }^{\circ} \mathrm{C}$ dan waktu pengeringan 2.54 jam. Parameter yang dihasilkan yaitu nilai warna (nilai chroma) sebesar 21.22, kadar vitamin C sebesar 5.8 mg 100 g- $^{1}$, kadar air sebesar $10.56 \%$, dan kadar gula total sebesar $49.82{ }^{\circ}$ Brix. Gambar kondisi optimal dari semua parameter tersebut terdapat pada Gambar 2.

\section{Validasi Kondisi Optimal}

Validasi dilakukan untuk menguji kebenaran data prediksi yang dihasilkan. Batas toleransi nilai validasi yang diberikan adalah maksimal $10 \%$ dari nilai prediksi. Nilai toleransi yang didapatkan pada penelitian ini adalah sebesar $5.43 \%$ mendekati nilai prediksi dari kondisi optimal yang dihasilkan yaitu di bawah $10 \%$ dengan kata lain kondisi optimal yang didapatkan sesuai dengan nilai prediksi. Hasil validasi tersebut dapat dilihat pada Tabel 3.

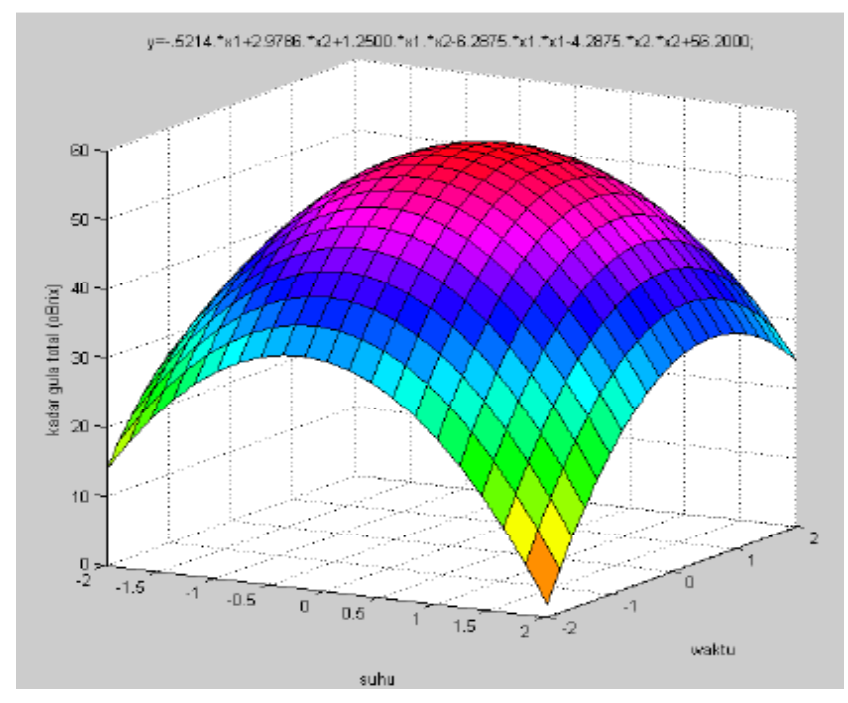

Gambar 1. Surface plot kadar gula total manisan kering cabai merah

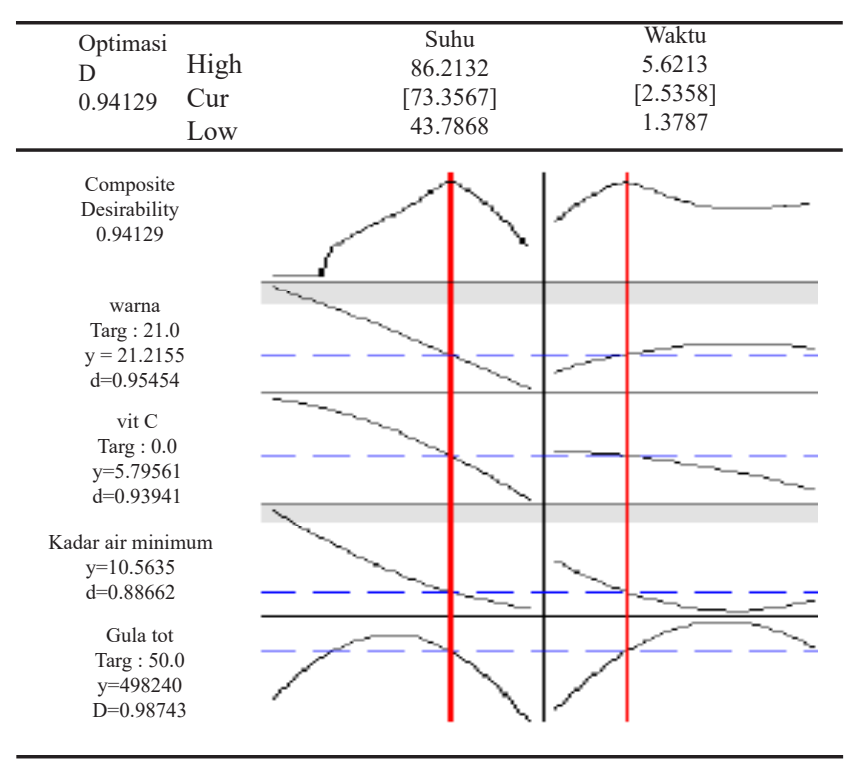

Gambar 2. Kondisi optimal kombinasi faktor reaksi 
Tabel 3. Validasi kondisi optimal

\begin{tabular}{ccccccc}
\hline Suhu $\left({ }^{\circ} \mathrm{C}\right)$ & Waktu (jam) & Parameter & Nilai Prediksi & Nilai Validasi & Keakuratan $(\%)$ & Toleransi $(\%)$ \\
\hline 73.36 & 2.54 & warna & 21.22 & 23.35 & 90.88 & 9.12 \\
& vitamin C & 5.80 & 6.04 & 96.04 & 3.96 \\
& kadar air & 10.56 & 11.05 & 95.60 & 4.40 \\
& kadar gula total & 49.82 & 52.00 & 95.77 & 4.23 \\
\hline & Rata-rata toleransi (\%) \\
& & & & 5.43 \\
\hline
\end{tabular}

\section{KESIMPULAN}

Kondisi optimal pada proses pengeringan manisan cabai merah didapatkan pada suhu $73.36{ }^{\circ} \mathrm{C}$ dan waktu pengeringan 2.54 jam dengan nilai desirability sebesar 0.94 . Manisan kering cabai merah yang dihasilkan memiliki nilai warna (chroma) sebesar 21.22, kadar vitamin C sebesar 5.80 $\mathrm{mg} / 100 \mathrm{~g}$, kadar air sebesar $10.56 \%$, dan kadar gula total sebesar $49.82{ }^{\circ}$ Brix.

Hasil validasi kondisi optimal menunjukkan bahwa nilai chroma yang didapatkan adalah 23.35 dengan batas toleransi sebesar $9.12 \%$. Kadar vitamin $\mathrm{C}$ yang didapatkan adalah $6.04 \mathrm{mg} / 100 \mathrm{~g}$ dengan batas toleransi sebesar 3.96\%. Kadar air yang didapatkan adalah $11.05 \%$ dengan batas toleransi sebesar $4.40 \%$. Kadar gula total yang didapatkan adalah $52{ }^{\circ}$ Brix dengan batas toleransi sebesar $4.23 \%$. Batas toleransi nilai validasi yang diberikan adalah maksimal $10 \%$ dari nilai prediksi, dengan demikian hasil validasi kondisi optimal yang didapatkan sesuai dengan hasil prediksi.

\section{DAFTAR PUSTAKA}

Achyadi, N.S., A. Hidayanti. 2004. Pengaruh konsentrasi bahan pengisi dan konsentrasi sukrosa terhadap karakteristik fruit leather Campedak (Artocarpus campeden L.). http://www.unpas.ac.id [23 Maret 2013]

Burdulu, HS., N. Koca, F. Karadeniz. 2006. Degradation of vitamin $\mathrm{C}$ in citrus juice concentrate during storage. J Food Eng 74 (2) : 211-216.
Deman, J.M. 1997. Kimia Makanan. ITB Bandung. Bandung.

Kusnandar, F. 2010. Kimia Pangan : Komponen Makro. PT. Dian Rakyat. Jakarta.

Muchtadi, D., B. Anjarsari. 1995. Penanganan pascapanen dalam meningkatkan nilai tambah komoditas sayuran. Prosiding. Seminar Ilmiah Nasional Komoditas Sayuran. Lembang. 91-105 Hal

Sanguansri, L., I. Gould, P. Drew. 1995. Improved quality for dry tomatoes. Final Report No. TM-304, Australian Food Industry Science Centre. Werribee. Victoria.

SII, 0718-83. Mutu Manisan Kering Buah-Buahan. Standar Industri Indonesia.

Taib, G., E.G. Said, S. Wiraatmaja. 1987. Operasi Pengeringan pada Pengolahan Hasil Pertanian. PT. Mediyatama Sarana Perkasa. Jakarta.

Wati, W.E. 2011. Pengaruh konsentrasi larutan gula dan proses pengeringan pada pembuatan manisan kering belimbing wuluh (Averrhoa bilimbii). Skripsi. Universitas Djuanda Bogor. Bogor.

Wenck, DA., H. Baren, S.P. Dewan. 1980. Nutrition. Reston Publishing Company. Virginia. 